\title{
Synthesis and identification of organosoluble polyimides: thermal, photophysical and chemiluminescence properties
}

\author{
Mousa Ghaemy and Seyed Mojtaba Amini Nasab
}

Novel fluorescent polyimides (PIs) were prepared from a new diamine, 4-(4-(4-amino-2-(4,5-diphenyl-1H-imidazol-2-yl) phenoxy)phenoxy)-3-(4,5-diphenyl-1H-imidazol-2-yl)benzenamine, and three tetracarboxylic dianhydrides. The new symmetrical diamine was successfully synthesized by the nucleophilic substitution reaction of hydroquinone with 2-(2-chloro5-nitrophenyl)-4, 5-diphenyl-1H-imidazole (I). The PIs synthesized here are amorphous and soluble in polar aprotic solvents and demonstrate the ability to form films; their inherent viscosities ranged from 43 to $82 \mathrm{mlg}^{-1}$. The PIs had suitable thermal stability and relatively high $T_{\mathrm{g}}$ values $\left(245-274{ }^{\circ} \mathrm{C}\right), 10 \%$ weight loss temperatures in excess of $500^{\circ} \mathrm{C}$ and char yields at $600{ }^{\circ} \mathrm{C}$ in air up to $62 \%$. The Pls show emission in the solid state and in dilute $(0.20 \mathrm{~g}$ per $100 \mathrm{ml}) \mathrm{N}, \mathrm{N}$-dimethyl acetamide solution at $431-464 \mathrm{~nm}$ with photoluminescence $(\mathrm{PL})$ quantum yields in the range of $11-25 \%$. The chemiluminescence activity of PIs in the presence of peroxyoxalate was also investigated.

Polymer Journal (2010) 42, 648-656; doi:10.1038/pj.2010.57; published online 30 June 2010

Keywords: fluorescent; polyimides; solubility; synthesis; thermal stability

\section{INTRODUCTION}

Aromatic polyimides (Pls) generally possess excellent thermal, mechanical, electrical and chemical properties. Therefore, they have been used in many applications such as electronics, coatings and adhesives, composite materials and membranes. ${ }^{1-3}$ However, these polymers are difficult to process because of their high glass transition temperatures $\left(T_{\mathrm{g}}\right)$ or high melting temperatures $\left(T_{\mathrm{m}}\right)$ and their limited solubility in organic solvents. ${ }^{4,5}$ Considerable efforts have been made to improve the solubility and melting processability of PIs while maintaining their desired properties. ${ }^{6-8}$ Significant synthetic efforts in the area of high-performance polymers have been focused on improving the processability and solubility of PIs through the design and synthesis of new monomers. Various structural modifications can be made to the PI backbone to modify the polymer properties, such as insertion of flexible linkages on the main chain, ${ }^{9-13}$ use of noncoplanar ${ }^{14}$ or asymmetric monomers ${ }^{15-19}$ and incorporation of pendant groups in the polymer backbone, ${ }^{20-29}$ with results including lower interchain interactions or a reduced polymer chain stiffness. Depending on the type and amount of structural modifications, melting temperatures can be lowered and solubility improved, resulting in processable materials. Introducing bulky pendant substituents and heteroaromatic rings into PI chains has been considered to be an efficient method to provide not only enhanced solubility but also good thermal and thermo-oxidative stability. ${ }^{22}$ The rigidity based on the symmetry and aromaticity of the heteroaromatic ring contributes to the thermal stability, chemical stability and retention of mechanical properties of the resulting polymer at elevated temperatures, ${ }^{5}$ and the polarizability resulting from the nitrogen atom in the imidazole ring improves the polymer's solubility in organic solvents. ${ }^{18}$ The imidazole ring is a useful $n$-type building block with high electron affinity and good thermal stability that has been successfully incorporated in small molecules and polymers as the electron-transport component of organic light-emitting diodes. ${ }^{30-33}$ Moreover, lophine, 2, 4, 5-triphenylimidazole and its derivatives are well-known potential chemiluminescence (CL) compounds with significant analytical applications based on their fluorescence and CL. ${ }^{34,35}$

The present investigation deals with the synthesis and characterization of three PIs from a new monomer, 4-(4-(4-amino-2-(4,5-diphenyl$1 \mathrm{H}$-imidazol-2-yl)phenoxy)phenoxy)-3-(4,5-diphenyl-1H-imidazol-2-yl) benzenamine, bearing a triaryl imidazole pendant group that gives functionality to the side chains of the polymer and an ether linkage in the main chain that imparts flexibility to macromolecules. The presence of high-volume pendant groups is expected to result in a less-ordered structure, enhancing the solubility while maintaining good thermal stability. The aim of this study was to investigate the physical properties of these PIs, including their viscosity, solubility, thermal stability and their unique spectroscopic properties such as ultraviolet-visible absorption, photoluminescence (PL) and CL. 


\section{EXPERIMENTAL PROCEDURE}

\section{Materials}

All starting materials and reagents were purchased from either Merck (Darmstadt, Germany) or Fluka (Neu-Ulm, Germany). N-methyl-2-pyrrolidinone (NMP) and pyridine were purified by distillation under reduced pressure over calcium hydride and stored over $4 \AA$ molecular sieves. Dianhydrides such as pyromellitic dianhydride, $3,3^{\prime}, 4,4^{\prime}$-benzophenone tetracarboxylic dianhydride and bicyclo[2.2.2]oct-7-ene-2, 3, 5, 6-tetracarboxylic dianhydride were dried in a vacuum oven at $110^{\circ} \mathrm{C}$ for $5 \mathrm{~h}$. All other reagents and solvents such as $\mathrm{N}, \mathrm{N}$-dimethyl acetamide (DMAc), $\mathrm{N}, \mathrm{N}$-dimethyl formamide, NMP), dimethyl sulfoxide (DMSO), tetrahydrofuran and tetrachloroethane were used without further purification.

\section{Monomer synthesis}

2-(2-chloro-5-nitrophenyl)-4,5-diphenyl-1H-imidazole (I). In a $250 \mathrm{ml}$ roundbottomed two-necked flask equipped with a condenser, a magnetic stir bar and a nitrogen gas inlet tube, a mixture of $1.86 \mathrm{~g}(0.01 \mathrm{~mol})$ 2-chloro-5-nitrobenzaldehyde, $2.1 \mathrm{~g}(0.01 \mathrm{~mol})$ benzil, $5.39 \mathrm{~g}(0.07 \mathrm{~mol})$ ammonium acetate and $20 \mathrm{ml}$ glacial acetic acid was refluxed for $24 \mathrm{~h}$. On cooling, the precipitated white solid was collected by filtration and washed with ethanol and water. Yellow crystals were obtained in a yield of $3.55 \mathrm{~g}$ (95\% yield) and had a melting point of $218-220^{\circ} \mathrm{C}$. Fourier transform-infrared (FT-IR) $(\mathrm{KBr})$ at $\mathrm{cm}^{-1}: 3453$ $(\mathrm{NH}), 3124\left(\mathrm{C}-\mathrm{H}\right.$ aromatic), 1532, $1345\left(\mathrm{NO}_{2}\right)$ and $1684(\mathrm{C}=\mathrm{N})$. Anal. Calcd. (\%) for $\mathrm{C}_{21} \mathrm{H}_{14} \mathrm{ClN}_{3} \mathrm{O}_{2}$ : C, 67.20; H, 3.73; N, 11.20. Found: C, 67.00; H, 3.65; $\mathrm{N}, 11.35$.

2-(2-(4-(4-nitro-2-(4,5-diphenyl-1H-imidazol-2-yl)phenoxy)phenoxy)-5-nitroph-enyl)-4,5-diphenyl-1H-imidazole (II). In a $250 \mathrm{ml}$ round-bottomed twonecked flask equipped with a condenser, a magnetic stir bar and a nitrogen gas inlet tube, a mixture of $10 \mathrm{mmol}(1.1 \mathrm{~g})$ hydroquionone, $20 \mathrm{mmol}$ (7.5 g) 2-(2-chloro-5-nitrophenyl)-4, 5-diphenyl-1H-imidazole and $20 \mathrm{mmol}$ $(2.76 \mathrm{~g})$ anhydrous potassium carbonate in $20 \mathrm{ml}$ of dry DMAc was refluxed at $140^{\circ} \mathrm{C}$ for $12 \mathrm{~h}$ and then cooled. The mixture was then poured into water and the precipitate was collected by filtration and recrystallized from ethanol. The reaction is shown in Scheme 1. The yield of the reaction was $97 \%(7.6 \mathrm{~g})$, and the melting point was $275-278^{\circ} \mathrm{C}$. FT-IR ( $\mathrm{KBr}$ disk) at cm${ }^{-1}: 3453(\mathrm{NH})$, $3069\left(\mathrm{C}-\mathrm{H}\right.$ aromatic), $1608(\mathrm{C}=\mathrm{N}), 1588(\mathrm{C}=\mathrm{C}), 1532,1350\left(\mathrm{NO}_{2}\right)$ and 1234 (C-O). Anal. Calcd. for $\mathrm{C}_{48} \mathrm{H}_{42} \mathrm{~N}_{6} \mathrm{O}_{6}$ : C, $73.08 \% ; \mathrm{H}, 4.06 \%$; N, $10.66 \%$. Found: C, $72.93 \%$; H, $4.12 \%$; N, 10.55\%.

4-(4-(4-amino-2-(4,5-diphenyl-1H-imidazol-2-yl)phenoxy)phenoxy)-3-(4,5diphenyl-1H-imidazol-2-yl)benzenamine (III). Into a $250 \mathrm{ml}$ round-bottomed three-necked flask equipped with a dropping funnel, a reflux condenser and a magnetic stir bar, $7.88 \mathrm{~g}(0.01 \mathrm{~mol})$ 2-(2-(4-(4-nitro-2-(4,5-diphenyl-1H-imidazol-2-yl)phenoxy)phenoxy)-5-nitrophenyl)-4, 5-diphenyl-1H-imidazole and $0.2 \mathrm{~g}$ palladium on activated carbon $(\mathrm{Pd} / \mathrm{C}, 10 \%)$ were dispersed in $80 \mathrm{ml}$ ethanol. The suspension solution was heated to reflux, and $8 \mathrm{ml}$ of hydrazine monohydrate was slowly added to the mixture. After a further $5 \mathrm{~h}$ of reflux, the solution was filtered hot to remove $\mathrm{Pd} / \mathrm{C}$ and the filtrate was cooled to precipitate white crystals. The product was collected by filtration and dried in vacuum at $80^{\circ} \mathrm{C}$. The yield of the reaction was $85 \%(6.21 \mathrm{~g})$, and the melting point was $157-160^{\circ} \mathrm{C}$. FT-IR ( $\mathrm{KBr}$ disk) at $\mathrm{cm}^{-1}: 3362,3216\left(\mathrm{NH}_{2}\right), 3443(\mathrm{NH}$ imidazole), $3044(\mathrm{C}-\mathrm{H}$ aromatic), $1618(\mathrm{C}=\mathrm{N}), 1603(\mathrm{C}=\mathrm{C})$ and $1198(\mathrm{C}-\mathrm{O})$. $1 \mathrm{H}$ nuclear magnetic resonance $(\mathrm{NMR})\left(500 \mathrm{MHz}, \mathrm{CD}_{3} \mathrm{SOCD}_{3}\right): \delta 5.18(\mathrm{~s}$, $4 \mathrm{H}), 6.4-6.5(\mathrm{dd}, 2 \mathrm{H}, J=8.35 \mathrm{~Hz}), 6.7(\mathrm{~d}, 2 \mathrm{H}, J=8.35 \mathrm{~Hz}), 6.79-6.86(\mathrm{~d}, 2 \mathrm{H}$, $J=8.35 \mathrm{~Hz}), 7-7.14(\mathrm{~s}, 4 \mathrm{H}), 7.1-7.4(\mathrm{~m}, 20 \mathrm{H}), 11.93(\mathrm{~s}, 2 \mathrm{H})$. Anal. Calcd. for $\mathrm{C}_{48} \mathrm{H}_{36} \mathrm{~N}_{6} \mathrm{O}_{2}$ : C, 79.11\%; H, 4.94\%; N, 11.53\%. Found: C, 79.69\%; H, 4.58\%; $\mathrm{N}, 11.78 \%$.

\section{PI synthesis}

The following general procedure was used for the preparation of all PIs, as illustrated in Scheme 2. A $100 \mathrm{ml}$ three-necked round-bottomed flask equipped with a condenser, a magnetic stir bar, a nitrogen gas inlet tube and a calcium chloride drying tube was charged with $1 \mathrm{mmol}(0.73 \mathrm{~g})$ of diamine (III) and $10 \mathrm{ml}$ of dry NMP and the mixture was stirred at room temperature for $0.5 \mathrm{~h}$. Thereafter, $1 \mathrm{mmol}$ of dianhydride was added and the mixture was stirred for<smiles>CC(ONc1ccc(C(=O)c2ccccc2)cc1)C(N)=O</smiles>

(I)<smiles>O=[N+]([O-])c1ccc(Cl)c(-c2nc(-c3ccccc3)c(-c3ccccc3)[nH]2)c1</smiles><smiles>CC(=O)CCCOC(C)=O</smiles><smiles>O=[N+]([O-])c1ccc(Oc2ccc(Oc3ccc([N+](=O)[O-])c(-c4ccccc4)c3-c3ccccc3)cc2)c(-c2nc(-c3ccccc3)c(-c3ccccc3)[nH]2)c1</smiles><smiles>C=CCCCCN</smiles>

Scheme 1 Three-step synthesis procedure for the preparation of the monomer. 
<smiles>Nc1ccc(Oc2ccc(Oc3ccc(N)[nH+]c3-c3ccccc3)cc2)c(-c2nc(-c3ccccc3)c(-c3ccccc3)[nH]2)c1</smiles>

Ar:

$\mathrm{Pl}$<smiles>CC(C)=CCC=CCc1ccccc1</smiles>

$\mathrm{PI}-\mathrm{a}$

$\mathrm{PI}-\mathrm{b}$<smiles>C=C1C(C)C(C)C2C(C)C1C2C</smiles>

$\mathrm{Pl}-\mathrm{C}$

Scheme 2 Synthesis procedure for the preparation of polyimides.

$24 \mathrm{~h}$, forming a viscous solution of poly (amic acid) (PAA) in NMP. The chemical imidization of PAA was carried out by adding $3 \mathrm{ml}$ of a mixture of acetic anhydride/pyridine (6/4, v/v) into the PAA solution with stirring at ambient temperature for $1 \mathrm{~h}$. The mixture was then stirred at $130^{\circ} \mathrm{C}$ for $12 \mathrm{~h}$ to yield a homogeneous PI solution, which was poured slowly into ethanol to yield a precipitate that was collected by filtration, washed thoroughly with hot methanol and dried at $80^{\circ} \mathrm{C}$ in vacuum overnight. The yields were in the range of $89-95 \%$.

PI- $a$ : 90\% yield, FT-IR $\left(\mathrm{KBr}, \mathrm{cm}^{-1}\right): 3450(\mathrm{NH}$ imidazole), $3064(\mathrm{C}-\mathrm{H}$ aromatic), 1785, $1723(\mathrm{C}=\mathrm{O}$ imide $), 1603(\mathrm{C}=\mathrm{N}$ imidazole $), 1486(\mathrm{C}=\mathrm{C})$, $1375(\mathrm{C}-\mathrm{N})$ and $1234(\mathrm{C}-\mathrm{O}) .{ }^{1} \mathrm{H}$ NMR (DMSO- $\left.\mathrm{d}_{6}\right): \delta 12.45(\mathrm{~s}-2 \mathrm{H}), 7.22-8.45$ $(\mathrm{m}-32 \mathrm{H})$. Anal. Calcd. (\%) for $\left(\mathrm{C}_{58} \mathrm{H}_{34} \mathrm{~N}_{6} \mathrm{O}_{6}\right)_{\mathrm{n}}$ : $\mathrm{C}, 76.48 ; \mathrm{H}, 3.74 ; \mathrm{N}, 9.23$. Found: C, 76.35; H, 3.65; N, 9.52 .

PI- $b$ : 95\% yield, FT-IR $\left(\mathrm{KBr}, \mathrm{cm}^{-1}\right): 3449$ (NH imidazole), $3036(\mathrm{C}-\mathrm{H}$ aromatic), $1779,1725(\mathrm{C}=\mathrm{O}$ imide $), 1692(\mathrm{C}=\mathrm{O}), 1604(\mathrm{C}=\mathrm{N}$ imidazole $)$,

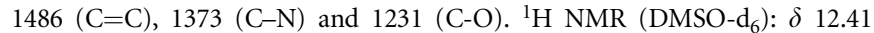
$(\mathrm{s}, 2 \mathrm{H}), 6.98-8.42(\mathrm{~m}, 36 \mathrm{H})$. Anal. Calcd. (\%) for $\left(\mathrm{C}_{65} \mathrm{H}_{38} \mathrm{~N}_{6} \mathrm{O}_{7}\right)_{\mathrm{n}}$ : C, 76.92; $\mathrm{H}$, 3.75; N, 8.28. Found: C, 76.42; H, 3.60; N, 8.36.

PI-c: $89 \%$ yield, FT-IR $\left(\mathrm{KBr}, \mathrm{cm}^{-1}\right): 3443$ (NH imidazole), 3055 (C-H aromatic), 1780, $1716(\mathrm{C}=\mathrm{O}$ imide $), 1603(\mathrm{C}=\mathrm{N}$ imidazole $), 1502$ $(\mathrm{C}=\mathrm{C}), 1381(\mathrm{C}-\mathrm{N})$, and $1223(\mathrm{C}-\mathrm{O}) .{ }^{1} \mathrm{H}$ NMR $\left(\mathrm{DMSO}-\mathrm{d}_{6}\right): \delta 12.39$ $(\mathrm{s}, 2 \mathrm{H}), 7.12-8.54(\mathrm{~m}, 30 \mathrm{H}), 6.5(\mathrm{~m}, 2 \mathrm{H}), 2.61(\mathrm{~m}, 4 \mathrm{H}), 2.28(\mathrm{~m}, 2 \mathrm{H})$. Anal. Calcd. (\%) for $\left(\mathrm{C}_{60} \mathrm{H}_{40} \mathrm{~N}_{6} \mathrm{O}_{6}\right)_{n}$ : C, 76.60; H, 4.25; N, 8.94. Found: C, 76.36; $\mathrm{H}, 4.43 ; \mathrm{N}, 8.72$.

\section{Measurements}

Elemental analysis was performed in a Flash EA 1112 series analyzer (Thermo Fisher Scientific, Milan, Italy). FT-IR spectra were recorded on a Bruker Tensor 27 spectrometer (Bruker, Karlsruhe, Germany). ${ }^{1} \mathrm{H}$ and ${ }^{13} \mathrm{C}$ NMR spectra were recorded on a $500 \mathrm{MHz}$ Bruker Avance DRX spectrometer (Bruker) in DMSO- $\mathrm{d}_{6}$ using tetramethyl silane as an internal reference. Inherent viscosities $\left(\eta_{\text {inh }}\right)$ were measured at $0.5 \mathrm{~g}$ per $100 \mathrm{ml}$ concentration using an Ubbelohde viscometer (Schott-Gerate, Hofheim, Germany) at $25^{\circ} \mathrm{C}$. Thermogravimetric analysis (TGA) was conducted using a TGA-50 analyzer (Shimadzu, Kyoto, Japan) in the temperature range of $50-600{ }^{\circ} \mathrm{C}$ under air atmosphere at a heating rate of $10^{\circ} \mathrm{Cmin}^{-1}$. Differential scanning calorimetry (DSC) analysis was performed on a Perkin-Elmer Pyris 6 DSC (Groningen, Netherlands) at a heating rate of $10^{\circ} \mathrm{C} \mathrm{min}^{-1}$ in air. $T_{\mathrm{g}}$ values were read at the middle of the transition in heat capacity and were taken from the second heating scan after cooling from $350{ }^{\circ} \mathrm{C}$ at a cooling rate of $20^{\circ} \mathrm{C} \mathrm{min}^{-1}$. Dynamic mechanical thermal analysis was carried out on a Polymer Laboratories instrument (Model MK-II; Walton-on-Thames, UK) over the temperature range of $25-350{ }^{\circ} \mathrm{C}$ at $1 \mathrm{~Hz}$ and a heating rate of $5{ }^{\circ} \mathrm{C} \mathrm{min}^{-1}$. Relaxation temperatures were determined from corresponding peak temperatures seen on damping $(\tan \delta)$ curves. Ultraviolet-visible and fluorescence emission spectra were recorded on a Cecil

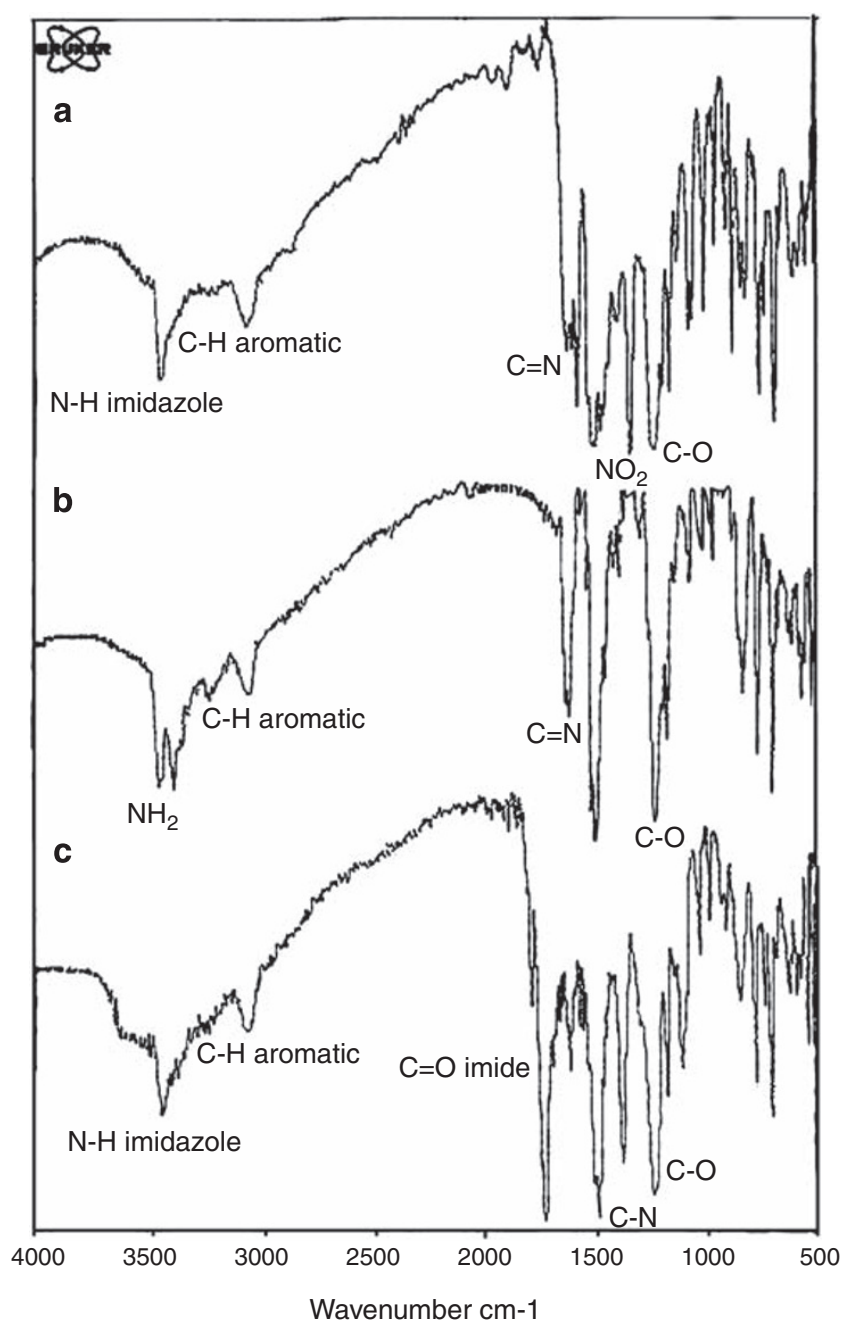

Figure 1 FT-IR spectra of the dinitro (a), diamine (b), and PI-a (c).

5503 (Cecil Instruments, Cambridge, UK) and Perkin-Elmer LS-3B spectrophotometers (Norwalk, CT, USA) (slit width $=2 \mathrm{~nm}$ ), respectively, using a dilute polymer solution $(0.20 \mathrm{~g}$ per $100 \mathrm{ml})$ in DMAc and films. Films used for the measurement of PL spectra were drop-coated from DMAc solutions $(0.20 \mathrm{~g}$ per $100 \mathrm{ml}$ ) onto quartz substrates. X-ray powder diffraction patterns were recorded 
by an X-ray diffractometer (GBC MMA instrument) with Be-filtered $\mathrm{Cu} \mathrm{K}$ $(1.5418 \AA$ ) operating at $35.4 \mathrm{kV}$ and $28 \mathrm{~mA}$. The $2 \theta$ scanning range was set between $4^{\circ}$ and $50^{\circ}$ at a scan rate of $0.05^{\circ}$ per s. CL detection was carried out with a homemade apparatus equipped with a model BPY47 photocell. The apparatus was connected to a personal computer through a suitable interface. Experiments were carried out with magnetic stirring in flat-bottomed glass cells of $15 \mathrm{~mm}$ diameter at room temperature.

Procedure for CL measurement. Bis (2, 4, 6-trichlorophenyl) oxalate (TCPO) was prepared from the reaction of 2, 4, 6-trichlorophenol with oxalyl chloride in the presence of triethylamine. Solution A was prepared with $1.0 \mathrm{ml}$ of TCPO $(0.01 \mathrm{M})$ and $0.5 \mathrm{ml}$-solution of monomer $\left(10^{-5} \mathrm{M}\right)$ and polymer $(0.20 \mathrm{~g}$ per $100 \mathrm{ml}$ ) in DMAc. Solution B contained $2.0 \mathrm{ml}$ of $3.0 \mathrm{M}$ hydrogen peroxide and $1.0 \mathrm{ml}$ of the catalyst sodium salicylate $(0.1 \mathrm{M})$ in methanol. Solution A was transferred into the instrument glass cell using a polypropylene syringe. Thereafter, $100 \mu \mathrm{l}$ of B stock solution was injected into the $3.0 \mathrm{~cm}$ quartz cuvette containing solution $\mathrm{A}$, and $\mathrm{CL}$ spectrum was recorded.

\section{RESULTS AND DISCUSSION}

\section{Monomer synthesis and characterization}

The objective of this study was the preparation of a novel fluorescent diamine material based on an imidazole pendant. Scheme 1 shows the synthesis of this new diamine compound, 4-(4-(4-amino-2-(4,5diphenyl-1H-imidazol-2-yl)phenoxy)phenoxy)-3-(4,5-diphenyl-1Himidazol-2-yl)benzenamine (III). Condensation of benzil with 2-chloro-5-nitrobenzaldehyde and ammonium acetate is well known as a classic but convenient synthetic method for the preparation of triaryl imidazole. The dinitro compound (II) containing the triaryl imidazole pendant group was synthesized by a nucleophilic aromatic substitution reaction of hydroquionone with the compound (I) in DMAc solvent and in the presence of $\mathrm{K}_{2} \mathrm{CO}_{3}$. The catalytic hydrogenation of dinitro into the corresponding diamine was accomplished using hydrazine hydrate in ethanol in the presence of a catalytic amount of $\mathrm{Pd} / \mathrm{C}$. Elemental analysis, FT-IR and ${ }^{1} \mathrm{H}$ and ${ }^{13} \mathrm{C}$ NMR spectroscopic techniques confirmed the structures of these com- pounds. The FT-IR spectra of the two synthesized compounds are presented in Figure 1. The nitro groups of compound (II) yielded two characteristic absorption bands at 1348 and $1545 \mathrm{~cm}^{-1}\left(-\mathrm{NO}_{2}\right.$ asymmetric and symmetric stretching). After reduction, these absorption peaks disappeared and the primary amino group showed the typical absorption pair at 3456 and $3354 \mathrm{~cm}^{-1}$ because of $\mathrm{N}-\mathrm{H}$ stretching. The ${ }^{1} \mathrm{H}$ NMR spectrum of compound (III) is presented in Figure 2. The signals at 5.2 and 11.9 p.p.m. are due to the $-\mathrm{NH}_{2}$ and $-\mathrm{NH}$ protons of the imidazole ring, respectively. Aromatic protons at $\delta 6.5-6.6(\mathrm{dd}, 2 \mathrm{H}, J=8.35 \mathrm{~Hz}), 6.7(\mathrm{~d}, 2 \mathrm{H}, J=8.35 \mathrm{~Hz})$, $6.9(\mathrm{~s}, 4 \mathrm{H})$ and 7.1-7.5 (m, 22H) p.p.m. showed the expected multiplicity and integration values. The ${ }^{13} \mathrm{C}$ NMR of diamine is shown with descriptions in Figure 3. These results clearly confirmed that the diamine (III) prepared herein is consistent with the proposed structure.

\section{Polymer synthesis and characterization}

Three PIs containing a hydroquinone unit in the main chain and a triaryl imidazole pendant group were prepared from the new diamine compound (III) with aromatic and cycloaliphatic dianhydrides (Scheme 2). Most conventional processing techniques involve the fabrication of PAA precursors, followed by thermal or chemical imidization. The new PIs were synthesized using two-step methods that were carried out by PAAs. First, diamine was dissolved in NMP and an equimolar amount of a dianhydride monomer was added to the solution. The solution was stirred for $24 \mathrm{~h}$ at room temperature, forming a viscous PAA solution. The chemical imidization with acetic anhydride and pyridine formed PIs with yields ranging from 85 to $92 \%$. The polymer structures were confirmed by elemental analysis, FT-IR and ${ }^{1} \mathrm{H}$ NMR spectroscopic techniques. The characteristic absorption bands of the five-membered imide ring appeared at 1785 and $1723 \mathrm{~cm}^{-1}$, corresponding to asymmetric and symmetric $\mathrm{C}=\mathrm{O}$ stretching, at $1375 \mathrm{~cm}^{-1}$ related to C-N stretching, and at 1095 and $765 \mathrm{~cm}^{-1}$ because of imide ring deformation, as shown in Figure 1c. Figure 4 presents the ${ }^{1} \mathrm{H}$ NMR spectrum of polyimide PI-a. Each

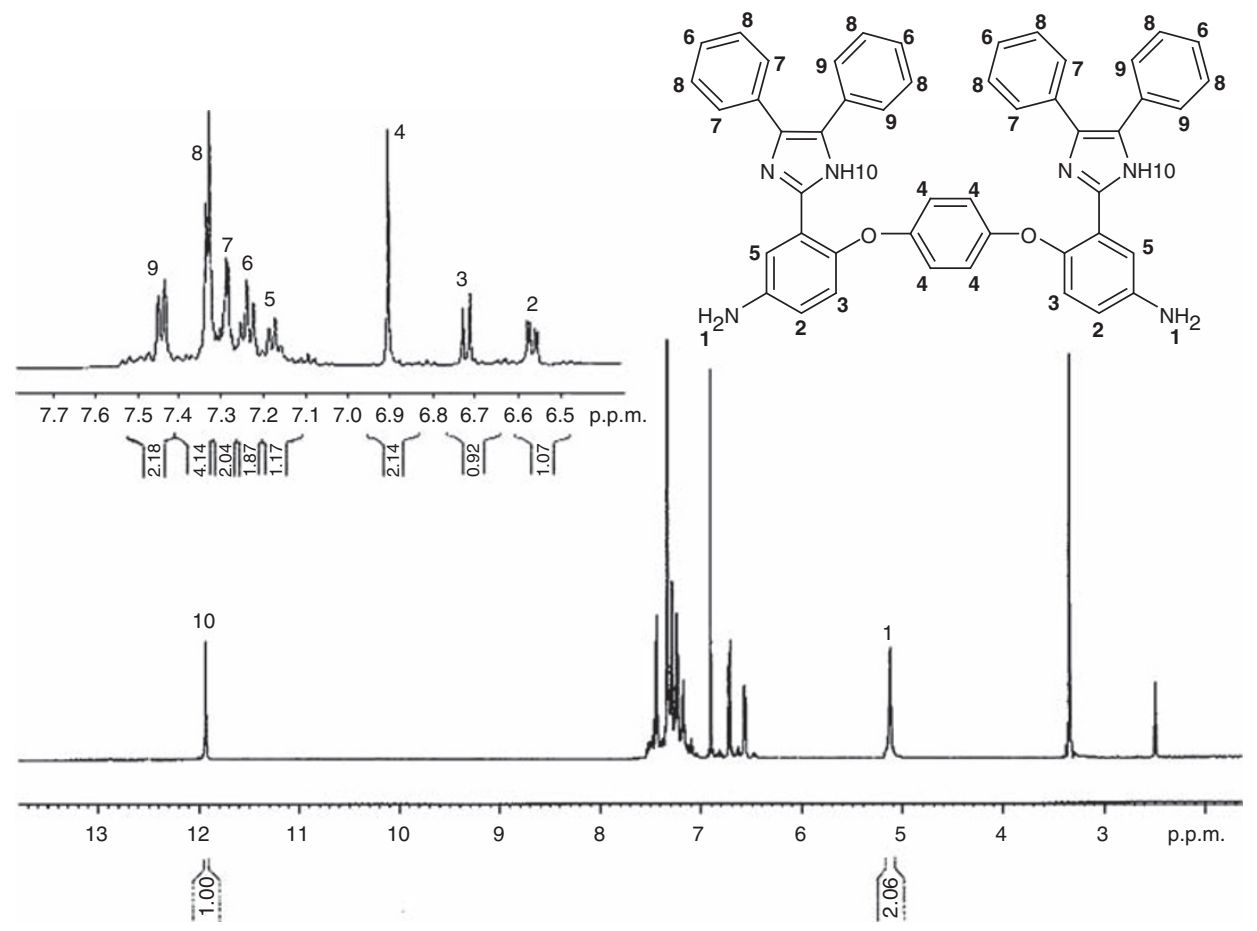

Figure $2{ }^{1} \mathrm{H}$ NMR spectra of diamine. 


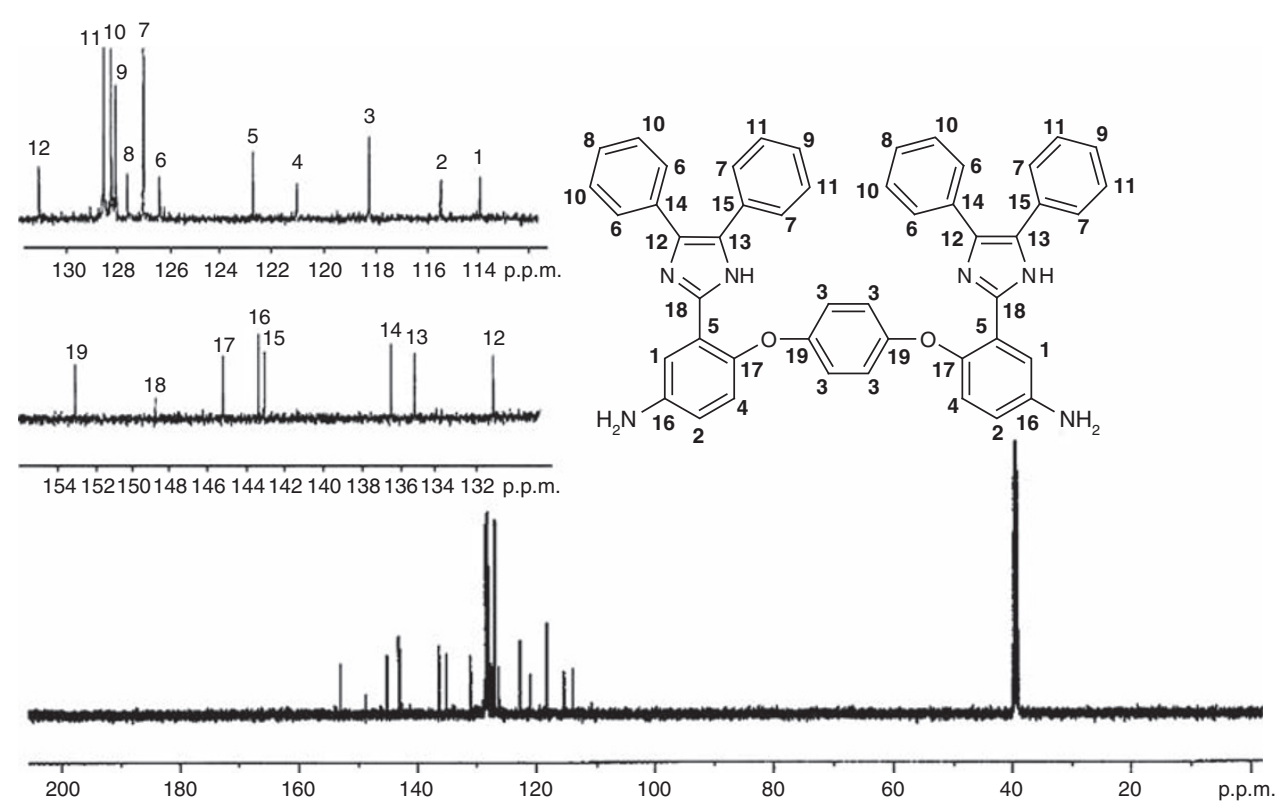

Figure $3{ }^{13} \mathrm{C}$ NMR spectra of diamine.

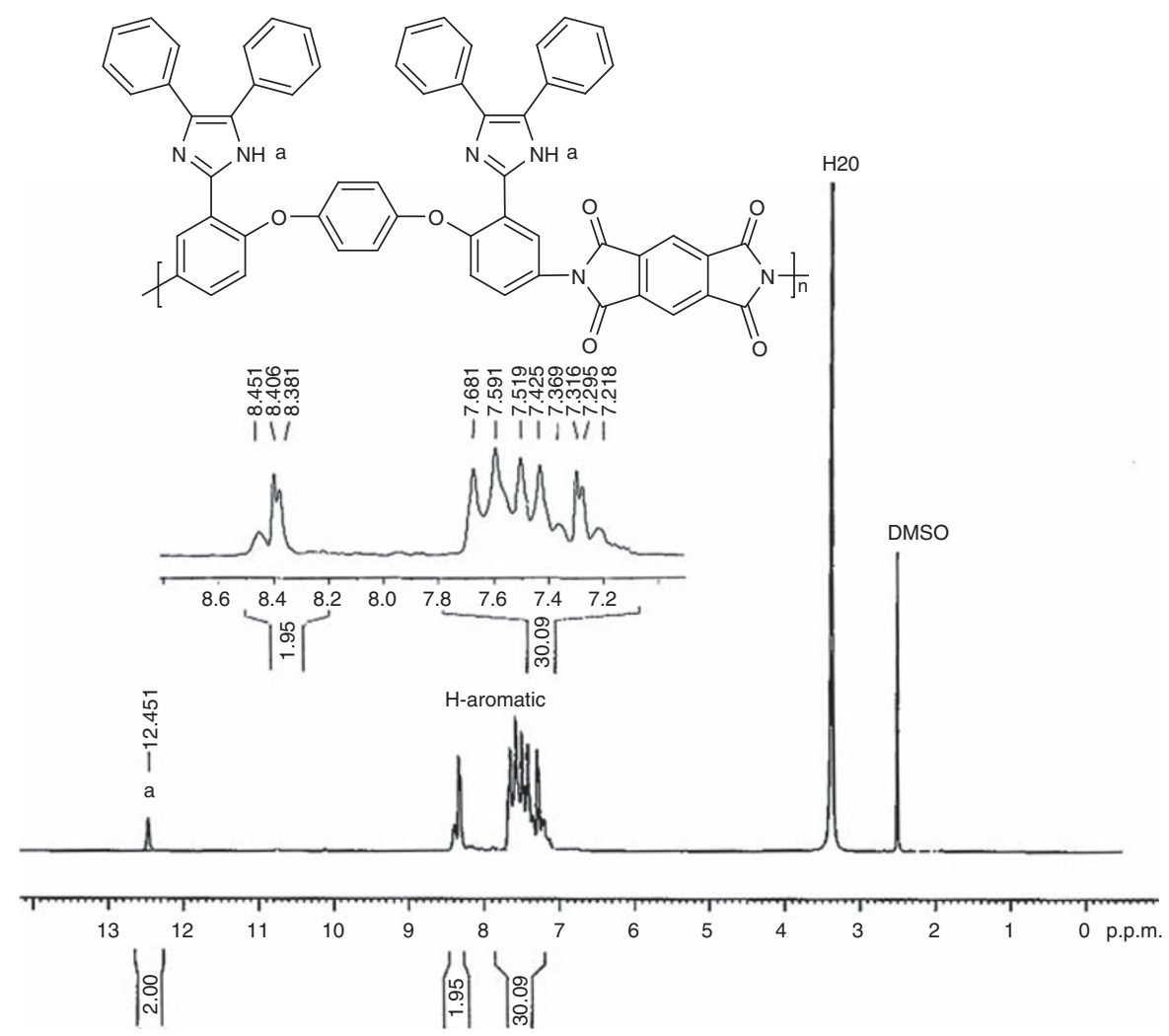

Figure $4{ }^{1} \mathrm{H}$ NMR spectra of $\mathrm{Pl}$-a.

proton is assigned in the figure and the total protons in the spectrum are consistent with the proposed chemical structure of the polymer. The polymer structures were also characterized using X-ray diffraction methods. Figure 5 shows the wide-angle X-ray diffractograms of the synthesized PIs. Wide-angle diffraction studies indicate that all PIs displayed almost amorphous patterns, which could be because of the presence of the pendant group that reduces the attraction between molecules and hinders regular macromolecular packing.

\section{Polymer properties}

Solubility and viscosity. The solubility of PIs was determined at a concentration of $5 \%(\mathrm{~W} / \mathrm{V})$ in a number of solvents, and the results 
are reported in Table 1. All of the prepared PIs exhibited excellent solubility in polar aprotic solvents such as NMP, DMAc, $N, N$-dimethyl formamide, DMSO, and even in less-polar solvents such as pyridine and $\mathrm{m}$-cresol at room temperature, but showed poorer solubility in dioxane and tetrachloroethane because of the low dielectric constant of the solvent. The good solubility should be the result of the introduction of the bulky pendant triphenyl imidazole group into the polymer backbone. The bulky pendant triphenyl imidazole group

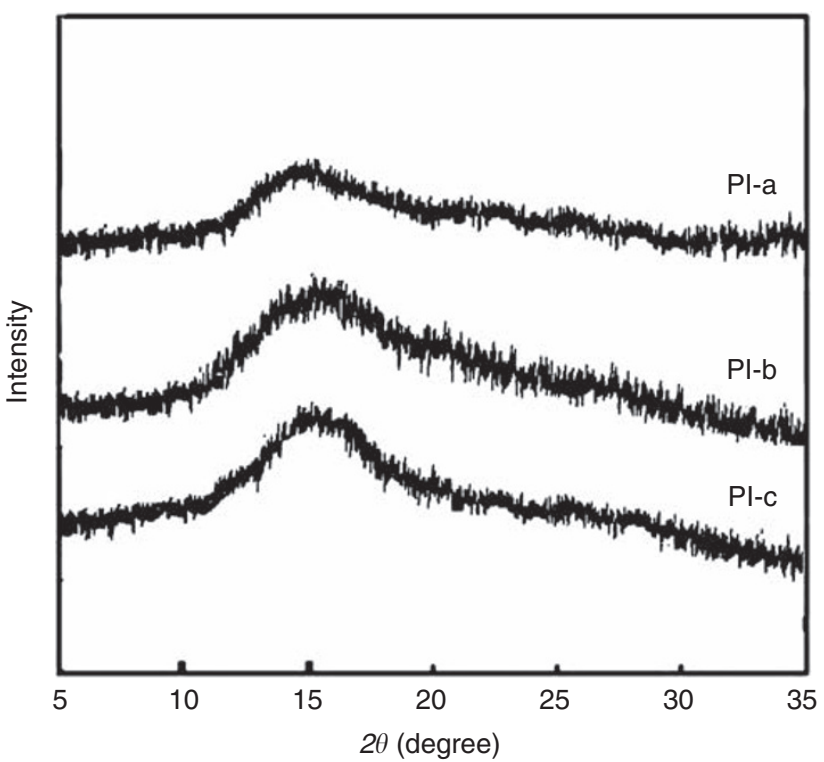

Figure 5 X-ray diffraction patterns of Pls. reduced the packing force and reduced the interchain interactions, allowing for better diffusion of solvent molecules, and also the polarizability resulting from the imidazole ring and ether linkages in the backbone improved their solubility in organic solvents. In addition, solubility varied depending on the dianhydrides used. PI-c, which was synthesized from a cycloaliphatic dianhydride, exhibited better solubility in dioxane and tetrachloroethane. The bicyclic unit in the structure of PI-c instead of the rigid phenyl group improves the solubility of this PI in comparison with PI-a and PI-b. Thus, all these polymers can be readily processed from solution. The obtained PIs had inherent viscosities $\left(\eta_{\text {inh }}\right)$ in the range from 43 to $82 \mathrm{ml} \mathrm{g}^{-1}$ at a concentration of $0.5 \mathrm{~g}$ per $100 \mathrm{ml}$ in NMP at $25^{\circ} \mathrm{C}$, as shown in Table 1 . All the polymers were able to produce tough and flexible films by solution casting. The films cast from these PIs are transparent, with a light yellow color.

Optical absorption, photoluminescent and chemiluminescent properties. The optical properties of PIs were investigated by ultravioletvisible, fluorescence and CL spectroscopy. The spectral data for the polymers in solution and in solid state are listed in Table 2. The diamine and PIs exhibited maximum ultraviolet absorption at 301$315 \mathrm{~nm}$, which can be attributed to the $\pi-\pi^{*}$ transitions resulting from the conjugation between the aromatic rings and nitrogen atoms. The optical behavior of the film specimens of these PIs revealed nearly identical results in solution state with a single absorbance at $307-321 \mathrm{~nm}$, which indicates that these polymers are unable to form a $\pi$-stacking structure in the solid state because of the bulky and twisted triaryl imidazole moiety. Figure 6a shows the PL spectra of the diamine and PIs in dilute $(0.20 \mathrm{~g}$ per $100 \mathrm{ml})$ DMAc solutions and also of PIs in the solid state. The fluorescence spectra of the diamine and PIs in DMAc solutions exhibited emission maxima at $405 \mathrm{~nm}$ and

Table 1 Solubility behavior and inherent viscosities of PIs

\begin{tabular}{|c|c|c|c|c|c|c|c|c|c|c|}
\hline Pl code & $N M P$ & DMSO & $D M A C$ & $D M F$ & m-cresol & THF & Dioxan & Pyridine & TCE & $\eta_{i n h}\left(100 \mathrm{~m} \mathrm{~g}^{-1}\right)^{\mathrm{a}}$ \\
\hline $\mathrm{PI}-\mathrm{a}$ & ++ & ++ & ++ & ++ & ++ & + & \pm & ++ & - & 0.82 \\
\hline PI-b & ++ & ++ & ++ & ++ & ++ & + & \pm & ++ & - & 0.72 \\
\hline $\mathrm{Pl}-\mathrm{C}$ & ++ & ++ & ++ & ++ & ++ & + & + & ++ & \pm & 0.43 \\
\hline
\end{tabular}

Abbreviations: DMAc, $N, N$-dimethyl acetamide; DMF, $N, N$-dimethyl formamide; DMSO, dimethyl sulfoxide; NMP, $N$-methyl pyrrolidone; PIs, polyimides; TCE, tetrachloroethan; THF, tetrahydrofuran. The solubility was determined using $5 \mathrm{~g}$ sample in $100 \mathrm{ml}$ of solvent. (++: Soluble at room temperature; +: Soluble on heating at $60^{\circ} \mathrm{C}$; \pm partially soluble on heating at $60^{\circ} \mathrm{C}$; insoluble on heating at $60^{\circ} \mathrm{C}$ ).

a Measured at a polymer concentration of $0.5 \mathrm{~g}$ per $100 \mathrm{ml}$ in NMP at $30^{\circ} \mathrm{C}$.

Table 2 Thermal characteristic and optical properties data of PIs

\begin{tabular}{|c|c|c|c|c|c|c|c|c|c|}
\hline \multirow[b]{3}{*}{ Pl code } & \multicolumn{4}{|c|}{ Thermal properties } & \multicolumn{5}{|c|}{ Optical properties } \\
\hline & \multirow[b]{2}{*}{$\mathrm{T}_{g}^{\mathrm{a}}(\mathrm{C})$} & \multirow[b]{2}{*}{$\mathrm{T}_{5}^{\mathrm{b}}(\mathrm{C})$} & \multirow[b]{2}{*}{$\mathrm{T}_{10} \mathrm{~b}(\mathrm{C})$} & \multirow[b]{2}{*}{ Char yield ${ }^{\mathrm{C}}(\%)$} & \multicolumn{3}{|c|}{ Solution ${ }^{\text {d }}$} & \multicolumn{2}{|c|}{ Film } \\
\hline & & & & & $\lambda_{a b s}(n m)$ & $\lambda_{e m}(n m)$ & $\phi_{f}^{\mathrm{e}}(\%)$ & $\lambda_{a b s}(n m)$ & $\lambda_{e m}(n m)$ \\
\hline $\mathrm{PI}-\mathrm{a}$ & 274 & 458 & 515 & 62 & 315 & 459 & 14 & 321 & 464 \\
\hline $\mathrm{PI}-\mathrm{b}$ & 262 & 424 & 487 & 45 & 308 & 450 & 11 & 316 & 460 \\
\hline $\mathrm{Pl}-\mathrm{C}$ & 245 & 375 & 412 & 17 & 301 & 423 & 25 & 307 & 431 \\
\hline
\end{tabular}

Abbreviations: DMAc, $N, N$-dimethyl acetamide; DSC, differential scanning calorimetry; PIs, polyimides; PL, photoluminescence; TGA, thermogravimetric analysis; $T_{\mathrm{g}}$, glass transition temperature; $T_{5}$, temperature for $5 \%$ weight loss; $T_{10}$, temperature for $10 \%$ weight loss; $\lambda_{\text {abs }}$, maximum absorption wavelength; $\lambda_{\text {em }}$, maximum emission wavelength.

aMidpoint temperature of baseline shift on the second DSC heating trace $\left(10^{\circ} \mathrm{Cmin}^{-1}\right.$, in air) of the sample after quenching from $350{ }^{\circ} \mathrm{C}$.

becomposition temperature, recorded using TGA at a heating rate of $20^{\circ} \mathrm{C} \mathrm{min}-1$ in air.

${ }^{C}$ Residual weight percentage at $600{ }^{\circ} \mathrm{C}$ in air.

dPolymer concentration of $10^{-5} \mathrm{moll}^{-1}$ in DMAc. They were excited at the abs $\max$ for both the solid and solution states. PI films for PL spectra were drop-coated from DMAc solutions ( $0.2 \mathrm{~g}$ per $100 \mathrm{ml}$ ) onto quartz substrates.

eFluorescence quantum yield relative to $10^{-5} \mathrm{M}$ quinine sulfate in $1 \mathrm{~N} \mathrm{H}_{2} \mathrm{SO}_{4}$ (aq) $\left(\phi_{\mathrm{f}}=0.55\right)$ as a standard. 

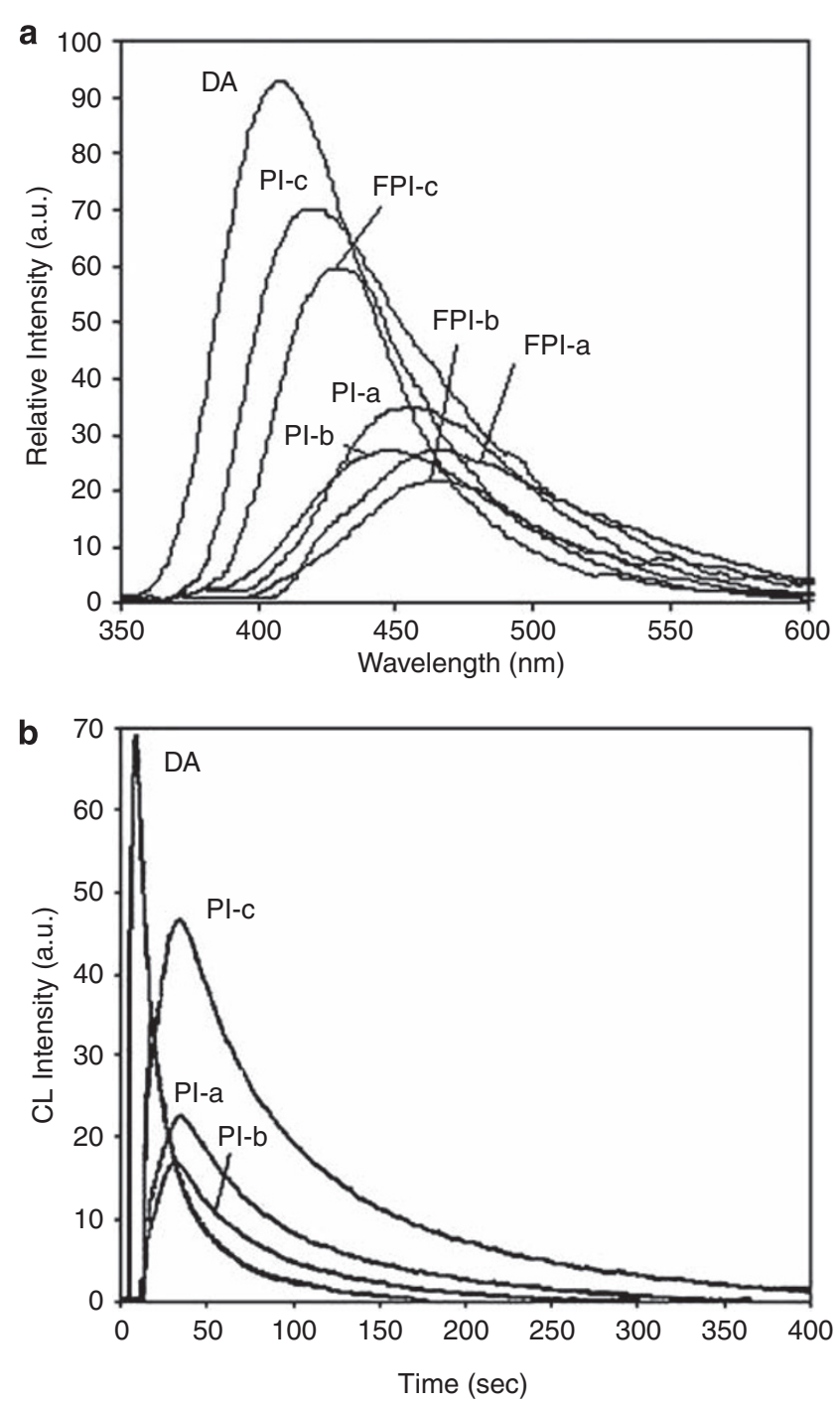

Figure $6 \mathrm{PL}$ spectra (a) for $\mathrm{PI}$ solutions ( $\mathrm{Pl}-\mathrm{a}, \mathrm{PI}-\mathrm{b}, \mathrm{PI}-\mathrm{c}$ ) and for $\mathrm{PI}$ films (FPI-a, FPI-b, FPI-c), and CL spectra (b) of solutions of the monomer and PIs.

$423-459 \mathrm{~nm}$, respectively. To measure PL quantum yields $\left(\phi_{\mathrm{f}}\right)$, dilute polymer solutions $(0.20 \mathrm{~g}$ per $100 \mathrm{ml})$ were prepared in DMAc. A $0.10 \mathrm{~N}$ solution of quinine in $\mathrm{H}_{2} \mathrm{SO}_{4}\left(\phi_{\mathrm{f}}=53 \%\right)$ was used as a reference. ${ }^{32}$ The PL efficiencies of PIs PI-a, PI-b and PI-c in DMAc solution are 14,11 and $25 \%$, respectively. The lower PL efficiency of PI-b (11\%) compared with the fluorescence quantum yield of PI-a $\left(\phi_{\mathrm{f}}=14 \%\right)$ can be attributed to the dissipation of energy into heat as a result of the facilitated bond rotation in the bridging carbonyl group between two phenyl rings present in PI-b. The aromatic cycloaliphatic PI PI-c exhibited a blue shift with $\phi_{\mathrm{f}}=25 \%$. The higher $\phi_{\mathrm{f}}$ of the fluorescence emission of this PI (PI-c) compared with aromatic PIs can be attributed to the effectively reduced conjugation and capability of charge-transfer complex formation by aliphatic diacids with the electron-donating diamine moiety in comparison with that of the stronger electron-accepting aromatic diacids. ${ }^{36}$ The PL behavior of films prepared from these PIs revealed nearly identical results as in solution state, with a single emission peak with maxima at $431-464 \mathrm{~nm}$, as shown in Figure 6a. The emission spectra of PI

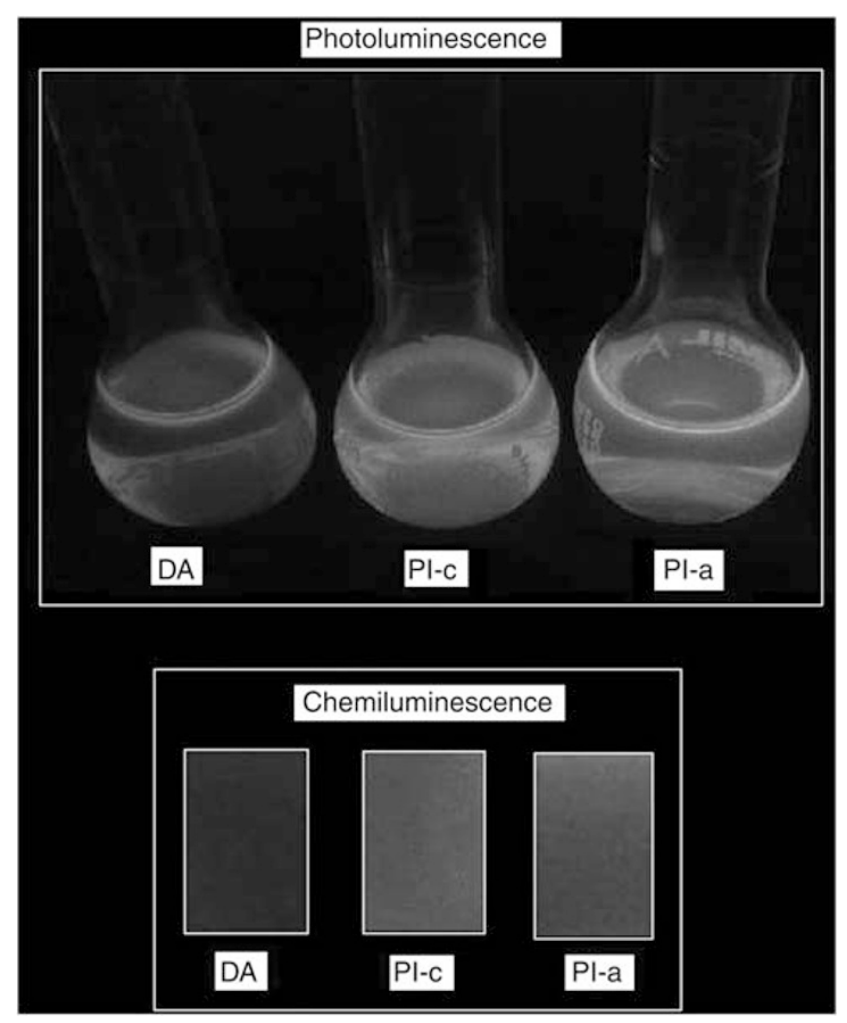

Figure 7 Fluorescence images of the monomer and $\mathrm{PI}$ solutions under ultraviolet irradiation. A full-color version of this figure is available at Polymer Journal online.

films showed a red shift $(5-10 \mathrm{~nm})$ versus the solution state and a small decrease in the intensity of fluorescent light with respect to the emission spectra of polymer solutions. These PIs have a bulky diaryl imidazole substituent at the meta position and a dianhydride moiety in the main chain, which limits close packing between aromatic chromophores in the solid state. This can effectively minimize the undesirable intramolecular charge-transfer and interchain interactions that result in low quantum yields for solid-state emissions or sizable shifts in solid-state emission wavelengths with respect to solutionphase emission spectra. Figure 7 shows the PL of the diamine and PIs PI-a and PI-c in solution under ultraviolet irradiation. Diamine and PI-c emitted fluorescent blue light while the aromatic PI-a exhibited greenish blue light.

The CL of the reaction between hydrogen peroxide and an activated derivative of oxalic acid such as TCPO in the presence of a fluorophore has been widely studied. ${ }^{37}$ We used this technique to study the $\mathrm{CL}$ arising from the reaction of TCPO with hydrogen peroxide in the presence of monomer and PIs. Preliminary experiments showed that the addition of a few drops of the stock solution of $\mathrm{H}_{2} \mathrm{O}_{2}$ to a DMAc solution containing TCPO and monomer results in a very intense blue CL that is very similar to the PL of the monomer (that is, $\lambda_{\max (\mathrm{em})}$ $=405 \mathrm{~nm}$ ). This experiment was repeated with the PIs and the result was a very intense CL as seen in Figure $6 \mathrm{~b}$. The higher CL intensity of aromatic-cycloaliphatic PI PI-c compared with aromatic PIs (PI-a and PI-b) could be due to the reduced conjugation in PI-c that resulted in a lower ability to form charge-transfer complexes. As can be seen in Figure 7, the PL and CL are essentially the same color; hence, the emission wavelength maxima in both processes should be similar. 


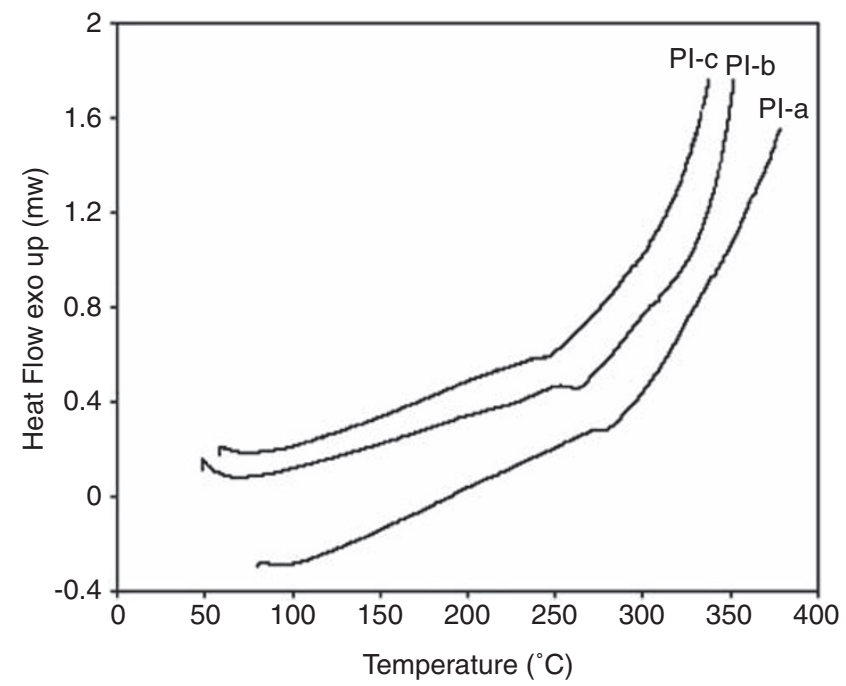

Figure 8 DSC curves of the Pls.

Thermal properties. Table 2 summarizes the DSC, dynamic mechanical thermal analysis and TGA methods used to evaluate the thermal properties of PIs and presents the data. The DSC curves of PIs are shown in Figure 8 , and $T_{\mathrm{g}}$ values were observed to range from 245 to $274^{\circ} \mathrm{C}$. As expected, $T_{\mathrm{g}}$ values depended on the structure of the dianhydride component, decreasing with increasing flexibility of the PI backbones based on the structure of the dianhydride. The bridging carbonyl group between two phenyl rings present in $3,3^{\prime}, 4,4^{\prime}$ benzophenone tetracarboxylic dianhydride facilitated bond rotation and reduced the $T_{\mathrm{g}}$ of PI-b in comparison with the $T_{\mathrm{g}}$ of PI-a. Among the synthesized PIs, PI-c based on bicyclic aliphatic dianhydride showed the lowest $T_{\mathrm{g}}$ value because of the absence of rigid phenyl groups that inhibit molecular motion. None of the PIs showed clear melting endotherms in the DSC thermograms. This result, together with the X-ray powder diffraction results shown in Figure 5, demonstrates the amorphous nature of these PIs. The amorphous nature of PIs can be attributed to the bulky pendant group that leads to an increase in steric hindrance, preventing close chain packing. This increases the fractional free volume between polymer chains and decreases the intra- and interchain interactions.

The viscoelastic relaxation behaviors of the polymers were subjected to dynamic mechanical thermal analysis experiments. Two relaxation processes can be observed above room temperature for all PIs. As a representative example, Figure 9 presents the dynamic mechanical thermal analysis results of the dynamic storage modulus and $\tan \delta$ as a function of temperature for two PIs. $\beta$-relaxation processes were observed in the range of room temperature to $200^{\circ} \mathrm{C}$, possibly because of the local molecular motions related to the diamine constituents of the polymer chain. The high temperature relaxation is an $\alpha$-relaxation process. The $\alpha$-relaxations correspond to the $T_{\mathrm{g}}$ values of PIs and the data are generally in good agreement with the $T_{\mathrm{g}}$ values obtained from DSC experiments.

The thermal stability of the polymers was evaluated by TGA in an air atmosphere. The TGA curves for the PIs are shown in Figure 10. The initial decomposition temperatures $\left(T_{\mathrm{i}}\right)$, the temperatures of $10 \%$ weight loss $\left(T_{10}\right)$ and the residual weight values were determined from the original TGA thermograms and are included in Table 2. All polymers exhibited good thermal stability with insignificant weight loss of up to $400^{\circ} \mathrm{C}$. The temperatures for $10 \%$ weight loss were in the range of $412-515^{\circ} \mathrm{C}$, indicating high thermal stability. A small weight

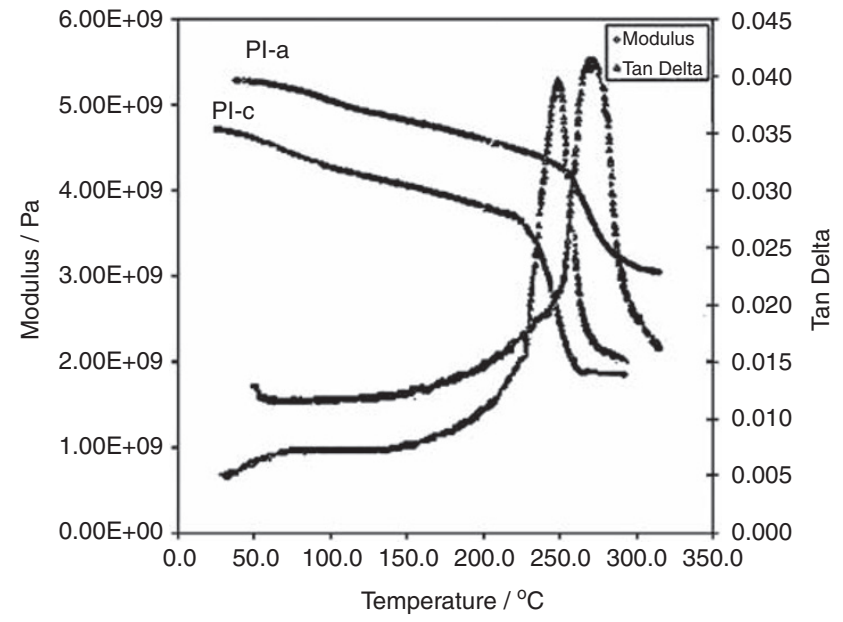

Figure 9 Dynamic mechanical thermal analysis curves of $\mathrm{PI}-\mathrm{a}$ and $\mathrm{PI}-\mathrm{c}$.

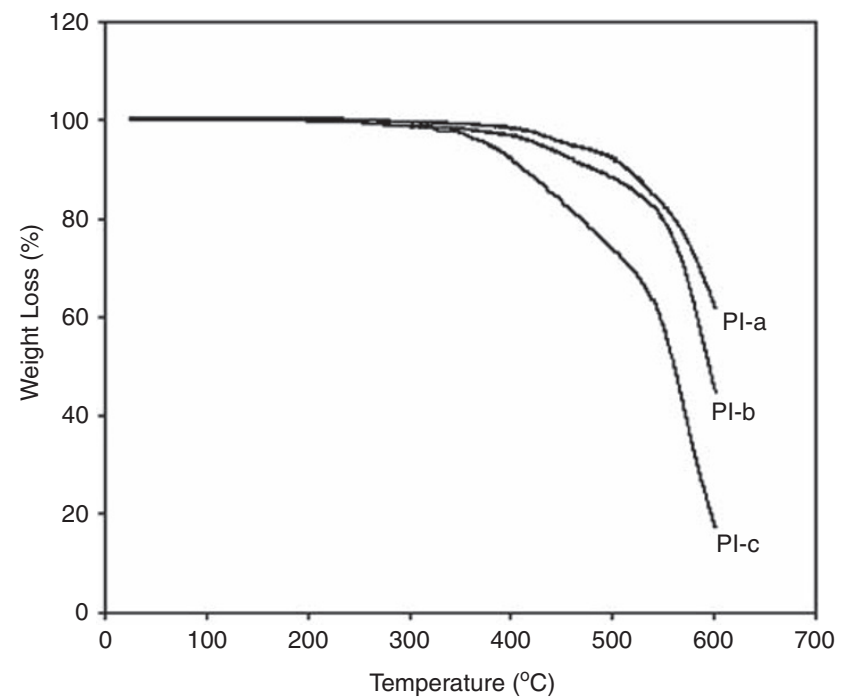

Figure 10 TGA curves of the PIs.

loss occurred at the beginning of the TGA curves of the polymers in the temperature range of $100-200^{\circ} \mathrm{C}$, which is due to the release of hygroscopic moisture. In addition, the residual weight retentions at $600{ }^{\circ} \mathrm{C}$ for the resulting PIs ranged from 23 to $62 \%$. PI-c has a lower thermal stability because of the introduction of the bicyclic aliphatic unit into the PI-c backbone. PI-a has a better thermal stability than PI-b because the carbonyl-bridging group between the two phenyl rings in the backbone of PI-b increases the flexibility of the polymer, thereby decreasing the thermal stability.

\section{CONCLUSIONS}

Three photoactive PIs have been prepared from a new symmetrical diamine monomer, 4-(4-(4-amino-2-(4,5-diphenyl-1H-imidazol-2-yl) phenoxy)phenoxy)-3-(4,5-diphenyl-1H-imidazol-2-yl)benzenamine, and aromatic and cycloaliphatic dianhydrides by a two-step chemical imidization method. These polymers had inherent viscosities from 0.43 to $0.82 \times 100 \mathrm{mlg}^{-1}$ and exhibited attractive properties that make them suitable for a variety of applications. The results presented here 
demonstrate that incorporating a bulky triaryl imidazole pendant group into the polymer backbone not only improved the solubility of the polymers in organic solvents while maintaining thermal stability but also revealed PL emission at $431-464 \mathrm{~nm}$ for solid state and solution $\left(\phi_{\mathrm{f}}=11-25 \%\right)$, and yielded CL as a result of the lophine-type moiety in the polymer structure. These characteristics suggest that these PIs have potential for use in sensor applications and also as soluble high-temperature polymers in engineering applications.

1 Wilson, D., Stenzenberger, H. D. \& Hergenrother, P. M. Polyimides (ed. Chapman and Hall, New York, 1990).

2 Ghosh, M. K. \& Mittal, K. L. Polyimides Fundamentals and Applications (ed,Marcel Decker, New York, 1996)

3 Yin, D. X., Li, Y. F., Yang, H. X. \& Yang, S. Y. Synthesis and characterization of novel polyimides derived from 1,1-bis[4-(4'-aminophenoxy)phenyl]-1-[3", $5^{\prime \prime}$-bis(trifluoromethyl)phenyl]-2,2,2-trifluoroethane. Polymer 46, 3119-3127 (2005).

4 Frazer, A. H. High Temperature Resistant Polymers (Inter Science, New York, Ch 2, 1968).

5 Zhang, S., Li, Y., Yin, D., Wang, X., Zhao, X., Shao, Y. \& Yang, S. Study on synthesis and characterization of novel polyimides derived from 2,6-Bis(3-aminobenzoyl) pyridine. Eur. Polym. J. 41, 1097-1107 (2005).

6 Hu, Z., Yin, Y., Kita, H., Okamoto, K. I., Suto, Y., Wang, H. \& Kawasato, H. Synthesis and properties of novel sulfonated polyimides bearing sulfophenyl pendant groups for polymer electrolyte fuel cell application. Polymer. 48, 1962-1971 (2007).

7 Yeganeh, H. \& Mehdipour-Ataei, S. Preparation and properties of novel processable polyimides derived from a new diisocyanate. J. Polym. Sci. Part A Polym. Chem. 38, 1528-1532 (2000).

8 Tsuda, Y., Yoshida, T. \& Kakoi, T. Synthesis of soluble polyimides based on alicyclic dianhydride in ionic liquids. Polymer. J. 38, 88-90 (2006).

9 Chen, S., Yin, Y., Kita, H. \& Okamoto, K. I. Synthesis and properties of sulfonated polyimides from homologous sulfonated diamines bearing bis(aminophenoxyphenyl)sulfone. J. Polym. Sci. Part A: Polym. Chem. 45, 2797-2811 (2007).

10 Tsuda, Y., Kojima, M., Matsuda, T. \& Oh, J. M. Soluble polyimides based on long-chain alkyl groups via amide linkages. Polymer. J. 40, 354-366 (2008).

11 Wang, X. L., Li, Y. F., Zhang, S. J., Ma, T., Shao, Y. \& Zhao, X. Synthesis and characterization of novel polyimides derived from pyridine-bridged aromatic dianhydride and various diamines. Eur. Polym. J. 42, 1229-1239 (2006).

12 Liu, J. G., Nakamura, Y., Shibasaki, Y., Ando, S. \& Ueda, M. Synthesis and characterization of high refractive index polyimides derived from 4,40-(p-phenylenedisulfanyl)dianiline and various aromatic tetracarboxylic dianhydrides. Polymer. J. 39, 543-550 (2007).

13 Shao, Y., Li, Y., Zhao, X., Ma, T., Gong, C. \& Yang, F. Synthesis and characterization of soluble polyimides derived from a novel unsymmetrical diamine monomer: $1,4-\left(2^{\prime}, 4^{\prime \prime}-\right.$ diaminodiphenoxy)benzene. Eur. Polym. J. 43, 4389-4397 (2007).

14 Liaw, D. J., Huang, C. C \& Chen, W. H. Color lightness and highly organosoluble fluorinated polyamides, polyimides and poly(amide-imide)s based on noncoplanar 2,2'-dimethyl-4,4'-biphenylene units. Polymer. 47, 2337-2348 (2006).

15 Shao, Y., Li, Y. F., Zhao, X., Wang, X. L., Ma, T. \& Yang, F. C. Synthesis and properties of fluorinated polyimides from a new unsymmetrical diamine: 1,4-(2'-Trifluoromethyl4',4"-diaminodiphenoxy)benzene. J. Polym. Sci. Part A Polym. Chem. 44, 6836-6846 (2006).

16 Sasaki, T., Moriuchi, H., Yano, S. \& Yokota, R. High thermal stable thermoplasticthermosetting polyimide film by use of asymmetric dianhydride (a-BPDA). Polymer. 46, 6968-6975 (2005).
17 Hsiao, S. H. \& Lin, K. H. Polyimides derived from novel asymmetric ether diamine. J. Polym. Sci. Part A: Polym. Chem. 43, 331-341 (2005).

18 Ghaemy, M. \& Alizadeh, R. Synthesis of soluble and thermally stable polyimides from unsymmetrical diamine containing 2,4,5-triaryl imidazole pendent group. Eur. Polym. J. 45, 1681-1688 (2009).

19 Choi, H., Chung, I. S., Hong, K., Park, C. E. \& Kim, S. Y. Soluble polyimides from unsymmetrical diamine containing benzimidazole ring and trifluoromethyl pendent group. Polymer. 49, 2644-2649 (2008).

20 Kung, Y. C., Liou, G. S. \& Hsiao, S. H. Synthesis and characterization of novel electroactive polyamides and polyimides with bulky 4-(1-adamantoxy)triphenylamine moieties. J. Polym. Sci. Part A: Polym. Chem. 47, 1740-1755 (2009).

21 Zhang, Q., Li, S., Li, W. \& Zhang, S. Synthesis and properties of novel organosoluble polyimides derived from 1,4-bis[4-(3,4-dicarboxylphenoxy)]triptycene dianhydride and various aromatic diamines. Polymer. 48, 6246-6253 (2007).

22 Ghaemy, M., Alizadeh, R. \& Behmadi, H. Synthesis of soluble and thermally stable polyimide from new diamine bearing $N$-[4-(9H-carbazol-9-yl)phenyl] formamide pendent group. Eur. Polym. J. 45, 3108-3115 (2009).

23 Ghaemy, M. \& Barghamadi, M. Synthesis and properties of organosoluble polyimides based on novel flourene-ring containing diacetamido-diamine. J. Appl. Polym. Sci. 112, 815-821 (2009).

24 Hsiao, S. H., Liou, G. S., Kung, Y. C., Pan, H. Y. \& Kuo, C. H. Electroactive aromatic polyamides and polyimides with adamantylphenoxy-substituted triphenylamine units. Eur. Polym. J. 45, 2234-2248 (2009).

25 Chang, C. W., Yen, H. J., Huang, U. Y., Yeh, J. M. \& Liou, G. S. Novel organosoluble aromatic polyimides bearing pendant methoxy-substituted triphenylamine moieties: Synthesis, electrochromic, and gas separation properties. J. Polym. Sci Part A: Polym. Chem. 46, 7937-7949 (2008).

26 Yang, C. P., Hsiao, S. H. \& Wu, K. L. Organosoluble and light-colored fluorinated polyimides derived from 2,3-bis(4-amino-2 trifluoromethylphenoxy)naphthalene and aromatic dianhydrides. Polymer. 44, 7067-7078 (2003)

27 Spiliopoulos, I. K. \& Mikroyannidis, J. A. Soluble, rigid-rod polyamide, polyimides, and polyazomethine with phenyl pendent groups derived from 4,4" -Diamino-3,5,3", $5^{\prime \prime}$ tetraphenyl-p-terphenyl. Macromolecules. 29, 5313-5319 (1996).

28 Yang, C. P. \& Su, Y. Y. Colorless and high organosoluble polyimides from 2,5-bis(3,4dicarboxyphenoxy)-t-butylbenzene dianhydride and aromatic bis(ether amine)s bearing pendent trifluoromethyl groups. Polymer. 46, 5778-5788 (2005).

29 Yang, C. P., Su, Y. Y. \& Hsu, M. Y. Organo-soluble and lightly-colored fluorinated polyimides based on 2,2-Bis[4-(3,4-dicarboxyphenoxy)phenyl]hexafluoropropane dianhydride and aromatic bis(ether amine)s bearing pendent trifluoromethyl groups. Polymer. J. 38, 132-144 (2006).

30 Mikroyannidis, J. A., Panayiotis, D., Panayiotis, V. I. \& Spiliopoulos, K. Synthesis, characterization and photophysics of poly(p-phenylenevinylene)-type polymers bearing substituted $2 \mathrm{H}$-imidazole rings in the backbone. Syn. Met. 145, 87-93 (2004).

31 Pan, Y., Tang, X., Zhu, L. \& Huang, Y. Synthesis and characterization of a new high-Tg photorefractive material. Eur. Polym. J. 43, 1091-1095 (2007).

32 Feng, K., Hsub, F. L., Van DerVeer, D., Bota, K. \& Xiu, R. Tuning fluorescence properties of imidazole derivatives with thiophene and thiazole. J. Photochem. Photobiol A: Chem. $165,223-228$ (2004).

33 Pan, Y. \& Tang, X. Synthesis and characterization of azobenzene-containing side-chain photorefractive polymers. Eur. Polym. J. 44, 408-414 (2008).

34 Nakashima, K., Fukuzaki, Y., Nomura, R., Shimoda, R., Nakamura, Y., Kuroda, N., Akiyama, S. \& Irgum, K. Fluorescence and chemiluminescence properties of newly developed lophine analogues. Dyes and Pigments 38, 127-136 (1998).

35 Fridman, N., Kaftory, M. \& Speiser, S. Structures and photophysics of lophine and double lophine derivatives. Sensors and Actuators B 126, 107-115 (2007).

36 Liou, G. S. \& Chang, C. W. Highly stable anodic electrochromic aromatic polyamides containing $N, N, N^{*}, N^{\prime}$-tetraphenyl-p-phenylenediamine moieties: synthesis, electrochemical, and electrochromic properties. Macromolecules 41, 1667-1674 (2008).

37 Stigbrand, M., Jonsson, T., Ponten, E., Irgum, K. \& Bos, R. Chemiluminescence in Analytical Chemistry (La Campana, Marcell Dekker, New York, 2000). 